\title{
Longitudinal assessment of hypercapnic ventilatory drive after tracheotomy in a patient with the Prader-Willi syndrome
}

\author{
D. Gozal, J.E. Torres, A.A. Menendez
}

\begin{abstract}
Longitudinal assessment of hypercapnic ventilatory drive after tracheotomy in a patient with the Prader-Willi syndrome. D. Gozal, J.E. Torres, A.A. Menendez. CERS Journals Ltd 1996.

ABSTRACT: The clinical course and changes in hypercapnic ventilatory drive over time were serially assessed before and after tracheostomy placement in a 14 year old, morbidly obese female patient with Prader-Willi syndrome, severe obstructive sleep apnoea, and obesity-hypoventilation syndrome.

A tracheostomy became necessary after supplemental oxygen and continuous positive airway pressure (CPAP) had failed to improve the severity of nocturnal hypoventilation. Continued improvement in the slope to rebreathing hyperoxic hypercapnia occurred from 2-10 weeks after tracheotomy in conjunction with night-time bilevel pressure ventilation, and remained unchanged thereafter. In contrast, increases in mean resting minute ventilation at an end-tidal carbon dioxide tension $\left(P \mathrm{ET}, \mathrm{CO}_{2}\right)$ of $8 \mathrm{kPa}(60 \mathrm{mmHg})$ were documented even after 30 weeks.

This case study illustrates the time-frame of dynamic ventilatory changes occurring after removal of upper airway resistance and normalization of nocturnal alveolar ventilation.

Eur Respir J., 1996, 9, 1565-1568.
\end{abstract}

\author{
Constance S. Kaufman Pulmonary \\ Research Laboratory \\ Depts of Pediatrics and Physiology \\ Tulane University School of Medicine \\ New Orleans \\ LA \\ USA. \\ Correspondence: D. Gozal, \\ Section of Pediatric Pulmonology, SL-37 \\ Tulane University School of Medicine \\ 1430 Tulane Avenue \\ New Orleans \\ LA 70112 \\ USA \\ Keywords: Control of breathing \\ sleep apnoea \\ Received: July 111995 \\ Accepted after revision January 191996
}

In adult patients with severe obstructive sleep apnoea syndrome (OSAS), a beneficial effect is observed 3 months after the reversal of upper airway resistance by tracheostomy placement. Both improved resting breathing pattern and hypercapnic ventilatory responses (HCVR) were reported in seven patients who were hypercapnic during wakefulness [1-3]. However, such beneficial effect has not yet been demonstrated in children with severe OSAS in whom tracheotomy may be required.

Prader-Willi syndrome (PWS) is the most common genetic disorder leading to obesity [4]. Hypogonadism, short stature with small hands and feet, behavioural disorders, as well as compulsive eating are characteristic of this syndrome [4]. However, with strict dietary intake restrictions, obesity may be prevented in PWS patients. Whilst absent or markedly reduced ventilatory response both to transient and isocapnic hypoxia during wakefulness $[5,6]$ are universally found both in obese and nonobese PWS patients, HCVR is blunted only in obese PWS patients [5, 7]. Furthermore, abnormal sleep patterns, including daytime somnolence, hypoventilation, oxygen desaturations during rapid eye movement (REM) sleep and abnormal sleep architecture, tend to occur more frequently in obese PWS [8], suggesting that additional obesity-related respiratory loads may contribute to modification of hypercapnic responsivity over time.

We report the case of a 14 year old obese female PWS patient with severe OSAS and obesity-hypoventilation syndrome, in whom resting ventilatory measures and HCVR were assessed prior to and serially after tracheotomy and nocturnal ventilatory support.

\section{Case report}

A 14 year old female previously diagnosed with PWS was urgently admitted following the insidious onset of fever, and diminished mental and physical activity levels over a 3 day period. Her past medical history was positive for recurrent urinary tract infections, uncontrollable appetite and feeding schedules, as well as obsessive compulsive behaviours, such as skin-pinching and hair-pulling. In addition, marked weight gain, loud snoring and daytime somnolence had been observed to develop since institution of trimonthly hormonal therapy with medroxyprogesterone for aggressive verbal behaviour. The patient's weight was $77 \mathrm{~kg}$, height $143 \mathrm{~cm}$, and calculated body mass index (BMI) $37.6 \mathrm{~kg} \cdot \mathrm{m}^{-2}$.

Physical examination disclosed a markedly obese patient, in no apparent distress, with a rectal temperature of $38.3^{\circ} \mathrm{C}$, a respiratory frequency $(f \mathrm{R})$ of 14 breaths $\cdot \mathrm{min}^{-1}$, pulse rate 114 breaths $\cdot \mathrm{min}^{-1}$, and blood pressure of 117/77 $\mathrm{mmHg}$. The patient was somnolent, although easily arousable on verbal command. No lymphadenopathy, icterus, cyanosis or clubbing were found. The head and neck were normal. Decreased breath sounds and diffuse rales were present over both lungs. The remainder of the examination revealed only physical stigmata characteristic of Prader-Willi syndrome, such as small hands and feet, sparse pubic, axillary and body hair, and small clitoris and labia minora.

Arterial blood gas values obtained whilst awake and breathing room air revealed a $\mathrm{pH}$ of 7.38 , an arterial oxygen tension $\left(\mathrm{Pa}_{\mathrm{a}} \mathrm{O}_{2}\right)$ of $8.7 \mathrm{kPa}(65 \mathrm{mmHg})$, and an 
Table 1. - Serial polysomnographic findings before (I), and 4 (II) and 9 (III) weeks following tracheotomy

\begin{tabular}{|c|c|c|c|}
\hline & I & II & III \\
\hline TST $h$ & 6.7 & 7.1 & 5.8 \\
\hline Apnoea index $n \cdot h^{-1}$ & 42.2 & 5.3 & 1.9 \\
\hline Duration of apnoea $\%$ TST & 19 & 2.4 & 1.0 \\
\hline $\begin{array}{c}\text { Baseline } P \mathrm{ET}, \mathrm{CO}_{2} \text { during sleep } \\
\mathrm{kPa} \\
\mathrm{mmHg}\end{array}$ & $\begin{array}{l}9.1 \\
68\end{array}$ & $\begin{array}{l}7.9 \\
59\end{array}$ & $\begin{array}{l}7.1 \\
53\end{array}$ \\
\hline $\begin{array}{r}\text { Peak } \begin{array}{r}P \text { ET, } \mathrm{CO}_{2} \\
\mathrm{kPa} \\
\mathrm{mmHg}\end{array}\end{array}$ & $\begin{array}{c}12.4 \\
93\end{array}$ & $\begin{array}{l}9.1 \\
68\end{array}$ & $\begin{array}{l}8.5 \\
64\end{array}$ \\
\hline $\begin{array}{l}\text { Duration of hypoventilation } \% \text { TST } \\
\left(P \mathrm{ET}, \mathrm{CO}_{2}>6.7 \mathrm{kPa}\right)\end{array}$ & 100 & 100 & 100 \\
\hline Baseline $\mathrm{S}_{\mathrm{a}, \mathrm{O}_{2}}$ during sleep $\%$ & $\stackrel{93}{93}\left(2 \mathrm{~L} \cdot \mathrm{min}^{-1} \mathrm{O}_{2} \mathrm{NC}\right)$ & $\begin{array}{l}96 \\
\text { (room air) }\end{array}$ & $\begin{array}{c}98 \\
\text { (room air) }\end{array}$ \\
\hline $\mathrm{Sa}, \mathrm{O}_{2}$ nadir $\%$ & 62 & 86 & 89 \\
\hline $\begin{array}{l}\text { Duration of desaturation \% TST } \\
\left(\mathrm{S}_{\mathrm{a}, \mathrm{O}_{2}}<90 \%\right)\end{array}$ & 14.4 & 4.6 & 0.7 \\
\hline REM \% TST & 12 & 17 & 24 \\
\hline
\end{tabular}

$\%$ TST: percentage of total sleep time; REM: rapid eye movement; $P$ ET, $\mathrm{CO}_{2}$ : endtidal carbon dioxide tension; $S_{\mathrm{a}, \mathrm{O}_{2}}$ : arterial oxygen saturation; $\mathrm{NC}$ : via nasal cannula.

arterial carbon dioxide tension $\left(\mathrm{Pa}_{\mathrm{a}}, \mathrm{CO}_{2}\right)$ of $6.9 \mathrm{kPa}(52$ $\mathrm{mmHg})$. A radiograph of the chest disclosed bilateral interstitial infiltrates, and therapy was instituted with intravenous antibiotics (cefuroxime and erythromycin), and supplemental oxygen at $2 \mathrm{~L} \cdot \mathrm{min}^{-1}$ delivered via nasal cannula. However, during sleep, loud snoring, and marked oxygen desaturations to the low $60 \mathrm{~s} \%$ were noted, and arterial blood gas measurements at this time revealed a $\mathrm{pH}$ of 7.25 , a $P \mathrm{a}, \mathrm{O}_{2}$ of $5.1 \mathrm{kPa}(38 \mathrm{mmHg})$, and a $\left(P \mathrm{a}, \mathrm{CO}_{2}\right)$ of $10.4 \mathrm{kPa}(78 \mathrm{mmHg})$. The patient was intubated and mechanically ventilated for several days, with rapid clearing of chest infiltrates and auscultatory findings, as well as normalization of arterial blood gas values. However, although minimal ventilatory support requirements (continuous positive airway pressure (CPAP) $6 \mathrm{cmH}_{2} \mathrm{O}$; inspiratory oxygen fraction $\left(\mathrm{FI}_{1} \mathrm{O}_{2}, 24 \%\right)$ were necessary during wakefulness, increasing support was necessary during sleep due to worsening hypercapnia and hypoxaemia (assist/control mode; $f \mathrm{R} 14$ breaths $\cdot \mathrm{min}^{-1}$; positive endexpiratory pressure (PIP) $40 \mathrm{cmH}_{2} \mathrm{O}$; positive end-expiratory pressure (PEEP) $6 \mathrm{cmH}_{2} \mathrm{O} ; F \mathrm{I}, \mathrm{O}_{2} 28 \%$ ). The patient was finally extubated on Day 5 after $12 \mathrm{~h}$ of CPAP, and 2 days later, an overnight polysomnogram was performed which confirmed the presence of severe OSAS (table 1).

On Day 9 of hospitalization, the patient developed cyanosis and bradycardia (45 beats $\cdot \mathrm{min}^{-1}$ ) during sleep. Arterial blood gas measurements on supplemental oxygen by mask revealed a $\mathrm{pH}$ of 7.07 and $\mathrm{Pa}_{\mathrm{a}} \mathrm{CO}_{2}$ of 12.1 $\mathrm{kPa}(91 \mathrm{mmHg})$, and the patient was intubated and mechanically ventilated. In the following 12 days, despite minimal ventilatory settings, several attempts to extubate the patient were unsuccessful due to development of severe alveolar hypoventilation $\left(P \mathrm{a}, \mathrm{CO}_{2} 9.3 \mathrm{kPa}(>70 \mathrm{mmHg})\right)$ during sleep. On day 20 , rebreathing ventilatory responses to hypercapnia were first assessed (see below), and 2 days later, a tracheostomy was performed. The patient was gradually weaned from daytime ventilation over the next 14 days. Arterial blood gases and oxygen saturation measured during wakefulness were within normal limits. To maintain adequate oxygenation and $P \mathrm{a}_{2}, \mathrm{CO}_{2} 6$
$\mathrm{kPa}(<45 \mathrm{mmHg})$ ventilatory support was provided during night-time sleep with bilevel positive airway pressure (BiPAP), ventilation (Respironics, Murry-sville, PA, USA) at the following settings: assist/control mode; PIP $20 \mathrm{cmH}_{2} \mathrm{O}$; PEEP $6 \mathrm{cmH}_{2} \mathrm{O}$; and $f \mathrm{R} 10$ breaths $\cdot \mathrm{min}^{-1}$. On Day 47, the patient was discharged on nighttime bilevel ventilation at the above settings, and underwent two additional sleep studies at 4 and 9 weeks after tracheostomy placement (table 1).

\section{Methods}

\section{Overnight polysomnography}

Overnight polysomnographic recordings were obtained without ventilatory support on three separate occasions, 2 weeks before, and 4 and 9 weeks after tracheostomy placement (table 1). Studies were conducted for $8 \mathrm{~h}$, in a quiet, darkened room with an ambient temperature of $24^{\circ} \mathrm{C}$. The following parameters were measured: chest and abdominal wall movement by respirator inductance plethysmography (Respitrace); heart rate by electrocardiogram (ECG); airflow was monitored with a thermistor (Physitemp; Clifton, NJ, USA); arterial oxygen saturation $\left(\mathrm{Sa}, \mathrm{O}_{2}\right)$ and end-tidal carbon dioxide tension $\left(P \mathrm{ET}, \mathrm{CO}_{2}\right)$ were assessed by pulse oximetry and infrared capnography (Nellcor N 1000; Nellcor Inc., Hayward, CA, USA); electro-oculogram (EOG), two-channel electroencephalogram (EEG), and chin electromyogram (EMG) were also monitored.

Scoring of respiratory and nonrespiratory variables during sleep was performed as described previously $[9,10]$, and the definition of apnoea as cessation of airflow for $10 \mathrm{~s}$ or longer was used.

\section{Ventilatory responses}

The patient was studied awake, sitting comfortably, and breathing spontaneously through either a cuffed endotracheal or tracheotomy tubes with identical inner diameters. 
The patient was connected to a Hans Rudolph pneumotachograph, and to a one-way rebreather valve (Hans Rudolph, Kansas City, MO, USA). Carbon dioxide partial pressure $\left(\mathrm{PCO}_{2}\right)$ was sampled continuously at the expiratory port of the respiratory valve, and analysed breathby-breath using a infrared microcapnometer (Columbus Instruments, Columbus, OH, USA). Dead space of this system was approximately $30 \mathrm{~mL}$. During each test, airflow was measured using a heated pneumotachometer and a pressure transducer (Validyne, Northridge, CA, USA). Breath-by-breath tidal volume ( $V \mathrm{~T})$ was obtained by analogue integration of the flow signal. Analogue output channels were continuously displayed on screen, and digitally acquired onto a MacIntosh Personal Computer System at $125 \mathrm{~Hz}$ sampling frequency, using MacLab Digital Acquisition Software (AD Instruments, Castle Hill, Australia). During subsequent off-line analysis with a peak-trough detection algorithm (Wavemetrics, Lake Oswedo, OR, USA), $(V \mathrm{~T})$ inspiratory time $(t \mathrm{I})$, and $\left(P \mathrm{ET}, \mathrm{CO}_{2}\right)$ were measured for each breath. From these, expiratory time $(t \mathrm{E}), f \mathrm{R}(60 / t \mathrm{I}+t \mathrm{E})$, and minute ventilation $\left(V^{\prime} \mathrm{E}\right)$ were calculated.

\section{Hypercapnic rebreathing ventilatory responses}

Ventilatory responses to increasing $P$ ET, $\mathrm{CO}_{2}$ were always measured in duplicate using a slightly modified version of the hyperoxic hypercapnic rebreathing technique described by READ [11]. A $13 \mathrm{~L}$ bag was filled with $70 \mathrm{~mL} \cdot \mathrm{kg}^{-1}$ body weight of $5 \% \mathrm{CO}_{2}$ in oxygen. The patient breathed room air for 3-4 min to establish baseline values, and was subsequently switched to the mixture bag at the end of a normal expiration. The test was continued until $P$ ET, $\mathrm{CO}_{2}$ reached $9.3-10 \mathrm{kPa}(70-75 \mathrm{mmHg})$. All tests were completed within $4 \mathrm{~min}$. Ventilatory responses to hypercapnia were expressed as the slope of $V^{\prime} \mathrm{E}$ versus $P$ ET, $\mathrm{CO}_{2}$. The normative range value for obese, healthy subjects is $2.95 \pm 0.51 \mathrm{~L} \cdot \mathrm{min}^{-1} \cdot \mathrm{mmHg}^{-1} P$ ET, $\mathrm{CO}_{2}$ [5]. Resting ventilation and mean $V^{\prime} \mathrm{E}$ at $P \mathrm{ET}, \mathrm{CO}_{2}$ of $8 \mathrm{kPA}(60 \mathrm{mmHg})$ were also recorded.

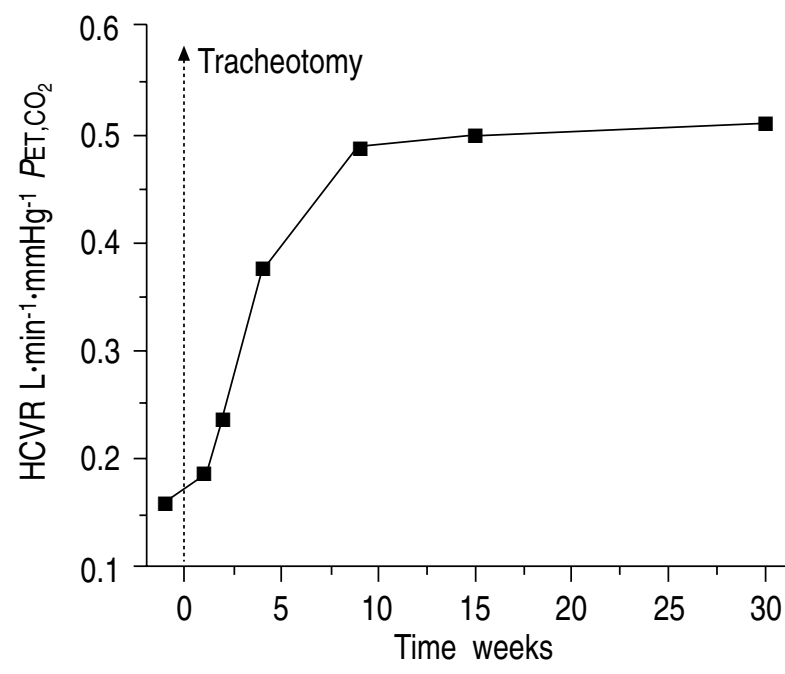

Fig. 1. - Serial changes in the slope of the hypercapnic ventilatory responses (HCVR) 2 days before, and at selected time-points of 30 weeks follow-up after tracheotomy (at the arrow). PET,CO : end-tidal carbon dioxide tension.

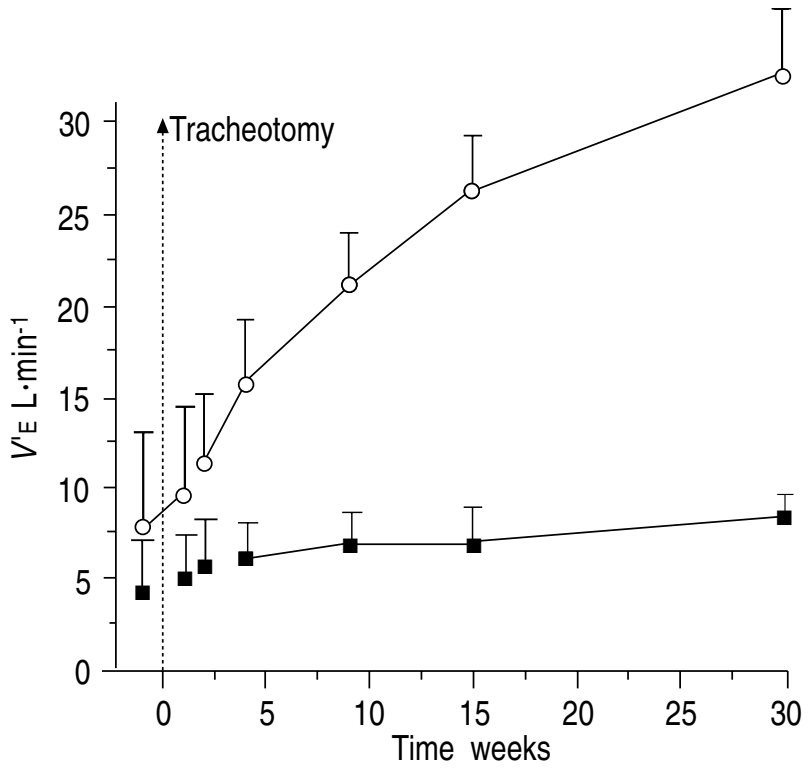

Fig. 2. - Mean $V^{\prime}$ E (+SD) measured during resting conditions (- and at $P$ ET, $\mathrm{CO}_{2}$ of $8 \mathrm{kPa}(60 \mathrm{mmHg})(-\mathrm{O}-) 2$ days before, and at selected time-points of 30 weeks follow-up after tracheotomy (at the arrow). $V$ 'E: minute ventilation; $P$ ET, $\mathrm{CO}_{2}$ : end-tidal carbon dioxide tension

\section{Results}

The results of hypercapnic ventilatory tests are shown in figures 1 and 2. Improvements in the slope of HCVR occurred within 2 weeks of tracheotomy and nocturnal bilevel pressure ventilatory support and plateaued at 10 weeks after surgery (fig. 1). Ongoing increases in resting $V^{\prime} \mathrm{E}$ as well as in $V^{\prime} \mathrm{E}$ measured at $P \mathrm{ET}, \mathrm{CO}_{2}$ of $8 \mathrm{kPa}$ $(60 \mathrm{mmHg})$ were still noticed 30 weeks after surgery (fig. 2).

\section{Discussion}

The present case documents the time course for recovery of hypercapnic ventilatory drive after removal of upper airway obstruction and night-time ventilatory support. Although no weight reduction occurred in our patient over time, marked increases in spontaneous ventilation during wakefulness, at $P$ ET, $\mathrm{CO}_{2}$ of $8 \mathrm{kPa}$ (60 torr), as well as in the HCVR slope occurred during the initial 10 weeks following tracheotomy, and the latter remaining unchanged thereafter (figs. 1 and 2). Thus, analogous to studies in adults [12], reduction of upper airway resistance, normalization of alveolar gas exchange during sleep, and prevention of sleep fragmentation due to apnoea resulted in gradual improvement of waking ventilatory measures, finally allowing for discontinuation of daytime ventilatory support 2 weeks after tracheotomy. However, although improved, persistent hypoventilation during sleep was still present after 9 weeks of treatment.

GuILlEMinaUlt and CUMmiskey [1] reported significant increases in the slope of HCVR after 12-16 weeks in five tracheotomized adult patients with OSAS, and comparable findings in three additional patients were documented within similar postoperative periods $[2,3]$. The 
time course of such improved hypercapnic drive was not serially assessed. More recently, increased ventilatory measures at a $P \mathrm{ET}, \mathrm{CO}_{2}$ of $8 \mathrm{kPa}(60 \mathrm{mmHg})$ were found in daytime hypercapnic OSAS patients as early as $48 \mathrm{~h}$ following institution of CPAP therapy, and continued to improve with continuing CPAP treatment for 2 weeks [13]. However, the slope of the HCVR remained unchanged over time [13]. Improvements in daytime ventilatory measures and chemosensitivity evolved slowly in our patient, despite normalization of alveolar ventilation during sleep with bilevel pressure ventilatory support. The absence of further improvement in this patient could indicate that she may have reached her "normal" HCVR, or that no further improvements would occur unless other therapeutic measures, such as weight loss or respiratory stimulants, were instituted.

Evaluation of control of breathing in awake, adult OSAS patients suggests that in patients with normocapnia during wakefulness, normal hypercapnic ventilatory and mouth occlusion pressures are found [14]. In contrast, in hypercapnic patients, the ventilatory $\mathrm{CO}_{2}$ response is usually depressed [15]. In nonobese children with OSAS, ventilatory responses to hypercapnia and hypoxia are similar to those found in healthy controls [16], suggesting that abnormal central respiratory drive is not a frequent component in the pathophysiology of OSAS in childhood.

The additional contribution of obesity to respiratory drive in our patient is unclear. Obesity leads to decreased chest wall compliance due to deposition of adipose tissue, and such elastic load may elicit early enhancement of neuromuscular respiratory output [17]. However, with prolonged mass loading, hypoventilation may develop over time [18]. In a recent study, we found that obese PWS patients had significantly diminished hypercapnic ventilatory slopes, whilst nonobese PWS patients demonstrated comparable slopes to those found in age-, genderand BMI-matched controls [5]. Thus, the absence of continued HCVR improvement after 10 weeks following tracheotomy in our patient may represent the net effect of daytime mass loading due to obesity, which may impinge on the complete recovery of HCVR to normal values [19], or an unrelated, diminished inborn hypercapnic ventilatory drive. Also worthy of mention was the relative bradypnoea recorded on admission in the presence of fever. We are uncertain of the exact significance of this sign, which could underlie either the absence of peripheral chemoreceptor response [6], or indicate disturbances in feedforward mechanisms originating in hypothalamic structures $[5,6]$.

In summary, the temporal improvements in waking ventilation and hypercapnic drive occurring after tracheotomy and bilevel pressure ventilation are reported in a PraderWilli Syndrome patient over a period of 30 weeks. This interesting case emphasizes the contribution of sleepdisordered breathing to blunted ventilatory responses to carbon dioxide and respiratory failure, and the potential for partial reversibility of such changes by therapeutic measures leading to adequate gas exchange.

Acknowledgements: Dr. Gozal is supported in part by a Clinical Investigator Development Award from the National Institute of Child Health and Development HD-01072-02.

\section{References}

1. Guilleminault C, Cummiskey J. Progressive improvement of apnea index and ventilatory response to $\mathrm{CO}_{2}$ after tracheostomy in obstructive sleep apnea syndrome. Am Rev Respir Dis 1982; 126: 14-20.

2. Auber-Tulkens G, Willems B, Veriter LL, Coche E, Stanescu DC. Increases in ventilatory responses to $\mathrm{CO}_{2}$ following tracheostomy in obstructive sleep apnea. Bull Eur Physiopathol Respir 1980; 16: 587-595.

3. Sullivan CE, Issa FG. Pathophysiological mechanisms in obstructive sleep apnea. Sleep 1980; 3: 235-246.

4. Butler MG. Prader-Willi syndrome: current understanding of cause and diagnosis. Am J Med Genet 1990; 35: 319-332.

5. Arens R, Gozal D, Omlin KJ, et al. 1994. Hypoxic and hypercapnic ventilatory responses in Prader-Willi syndrome. J Appl Physiol 1994; 77: 2224-2230.

6. Gozal D, Arens R, Omlin KJ, Davidson Ward SL, Keens TG. Absent peripheral chemosensitivity in Prader-Willi syndrome. J Appl Physiol 1994; 77: 2231-2236.

7. Orenstein DM, Boat TF, Owens RP, et al. The obesity hypoventilation syndrome in children with the PraderWilli syndrome: a possible role for familial decreased response to carbon dioxide. J Pediatr 1980; 97: 765-767.

8. Hertz G, Cataletto M, Feinsilver SH, Angulo M. Sleep and breathing patterns in patients with Prader-Willi Syndrome (PWS): effects of age and gender. Sleep 1993; 16: 366-371.

9. Marcus CL, Omlin KJ, Basinski DJ, et al. Normal polysomnographic values for children and adolescents. Am Rev Respir Dis 1992; 146: 1235-1239.

10. Rechtschaffen A, Kales A. A manual of standardized terminology, techniques and scoring systems for sleep stages of human subjects. Washington DC; National Institute of Health, Publication No. 204, 1968.

11. Read DJC. A clinical method for assessing the ventilatory response to carbon dioxide. Australasian Ann Med 1966; 16: 20-32.

12. Gold AR, Schwartz AR, Wise RA, Smith PL. Pulmonary function and respiratory chemosensitivity in moderately obese patients with sleep apnea. Chest 1993; 103: 1325-1329.

13. Berthon-Jones M, Sullivan CE. Time course of change in ventilatory response to $\mathrm{CO}_{2}$ with long-term CPAP therapy for obstructive sleep apnea. Am Rev Respir Dis 1987; 135: 144-147.

14. Rajagopal KR, Abbrecht PH, Tellis CJ. Control of breathing in obstructive sleep apnea. Chest 1984; 85: 174-180.

15. Garay SM, Rapoport D, Sorkin B, Epstein H, Feinberg I, Goldring RM. Regulation of ventilation in the obstructive sleep apnea syndrome. Am Rev Respir Dis 1981; 124: 451-457.

16. Marcus CL, Gozal D, Arens R, et al. Ventilatory and cardiac responses to hypercapnia and hypoxia during wakefulness in children with the obstructive sleep apnea syndrome. Am J Respir Crit Care Med 1994; 149: 715-721.

17. Sampson MG, Grassino A. Neuromechanical properties in obese patients during carbon dioxide rebreathing. $\mathrm{Am}$ J Med 1983; 75: 81-90.

18. Lopata M, Onal E. Mass loading, sleep apnea, and the pathogenesis of obesity hypoventilation. Am Rev Respir Dis 1982; 126: 640-645.

19. Marcus CL, Glomb WB, Basinski DJ, Davidson Ward SL, Keens TG. Developmental pattern of hypercapnic and hypoxic ventilatory responses from childhood to adulthood. J Appl Physiol 1994; 76: 314-320. 